\title{
Arterial Blood Velocity Measurement by Portable Wireless System for Healthcare Evaluation: The related effects and significant reference data
}

\author{
Azran Azhim ${ }^{1}$ and Yohsuke Kinouchi ${ }^{2}$ \\ ${ }^{1}$ Tokyo Denki University \\ ${ }^{2}$ The University of Tokushima \\ 1 Japan \\ 2Japan
}

\section{Introduction}

Arterial hemodynamic function is changed with aging, gender and regular exercise. Agerelated decreases in cardiovascular function are evident. The hallmarks of cardiovascular aging are decreased for maximum heart rate, ejection fraction, maximal oxygen intake, maximum cardiac output and artery compliance (Lakatta, 2002; Tanaka et al., 2000). On the other hand, we have found that exercise could improve the age-related deterioration in common carotid blood velocity (Azhim et al., 2007).

Gender-related differences in arterial hemodynamic functions such as systolic blood pressure (SBP) are demonstrated in some previous studies (London et al., 1995; Mitchell et al., 2004). It is suggested that younger women have lower brachial and ankle systolic blood pressure (SBP) and a lower ankle-arm pressure index than age-matched men (London et al., 1995). It has been reported that the incidence of cardiovascular complications increases with SBP (Kannel and Stokes, 1985) and that an increases in the pulsatile components of blood pressure is associated with higher cardiovascular risk in postmenopausal women (Darne, et al., 1989). However, there are a few studies in blood flow and velocity. In this chapter, we present the impact of gender on blood velocity waveform in common carotid artery (CCA). It was found that there is significant gender difference in some velocity waveforms in CCA (Azhim et al., 2007).

The ability to measure and interpret variations of pressure and flow in humans depends on an understanding of physiologic principles and is based on a heritage well over 100 years old. Studies of pressure preceded those of flow, since reliable tools were available for pressure measurement almost 100 years ago but for flow only 50 years ago (Nichols and O'Rourke, 2005).

There are two kinds of noninvasive technique to measure blood flow for portable wireless applications, one is a Doppler ultrasound method and the other is an optical one. The Doppler ultrasound was widely used to measure hemodynamic in blood vessels as carotid 
arteries that exist in the deep place from the human tissue (Prichard et al., 1979; Baskett et al., 1977; Gosling, 1977; He et al., 1992).

We have developed the telemetry measurement system in our laboratory which is capable to measure blood flow velocity in both aerial and aquatic environments. The device has enough performance for the measurement during physical exercise stress as well as at rest posture (Azhim et al., 2007; He et al., 1996; Jiang et al., 1994; Jiang et al., 1995). The measurement system with synchronized measurement of electrocardiogram and blood pressure will contribute to the extent of understandings in exercise physiology as well as further knowledge of arterial hemodynamic functions. We have shown that exercise has significant change to envelope waveform of CCA blood velocity in hemodynamic functions as evaluated from cross-sectional and intervention investigations (Azhim et al. 2007a).

Various telemetric techniques have been developed for ambulatory and noninvasive determination of bioelectrical and physiological signals in human subjects. Biomedical telemetry applications has brought numerous advantages such as comfort and portability, providing the critical information on improvements in quality of health care, efficiency in hospital administration capabilities and finally reduction at overall medical cost. Biomedical telemetry is a reliable tool for data gathering since the invention of integrated circuit (IC) technology which has enormous impacts on the contributions of microelectronics to biomedicine and health care applications (Azhim et al., 2009).

In the chapter, the usefulness of CCA velocities and the waveform indices after taking into account all relevant effects as reference value for clinical and healthcare applications are presented. In section 2, system is described the developed portable measurement system. Real-time monitor and data analysis are described in section 3. In section 4, data measurements and collections in the selected 202 healthy volunteers between the ages of 20 and 69 years are presented as a result by the following: Anthropometric data for the selected subjects, reference data for normal velocities in CCA and indices between the third to seventh decades after controlling for the effects of exercise training and gender, general agerelated decrease in flow velocities and change in the velocity waveform, regular exercise training improved blood velocity waveforms which markedly different in regularly exercise-trained middle-aged and older age-groups compared to the sedentary age peers, and gender-related difference in velocity and its indices. In last section, it can be concluded that normal CCA blood velocity parameters which are determined in a total of 202 healthy volunteers between the third and seventh age decade after adjustment for gender and exercise effects may contribute to improved means of healthcare monitoring and clinical evaluation.

\section{Measurement System}

The last three decades has shown rapid increase in the use of Doppler ultrasound devices for monitoring cardiovascular functions. Developments in Doppler technology have led to a vast increase in the number of non-invasive blood velocity investigations carried out in many areas of medicine. As with many rapidly expanding technologies there have been a considerable number of types of instrument developed and used in their institutions of origin, whereas only a few are in widespread portable device for exercise use.

We have developed a portable wireless system for measurement of blood velocity spectra in CCA with synchronized measurements of ECG and BP as shown in Fig. 1. In our previous 
studies, we have presented that the telemetry system has enough performance to get accurate data for estimation of blood circulation during physical exercise stress in both aerial and aquatic environments (Azhim et al., 2007a; Azhim et al., 2008; He et al., 1996; Jiang et al., 1994; Jiang et al., 1995). Measurements of blood velocity were noninvasively detected by using Doppler ultrasound method. The measurement system was consists of an ultrasound probe, a Doppler signal discriminator (DSD), an analog-digital (A/D) converter board and a laptop personal computer (PC), a wireless transmitter and a receiver as shown in Fig. 1. Data were transmitted using $315 \mathrm{MHz}$ FM/FSK transmitter which has $28.8 \mathrm{kbps}$ and $\sim 0.5 \mathrm{mV} / \mathrm{m}$ (feeble wave) for transmission speed and output, respectively.

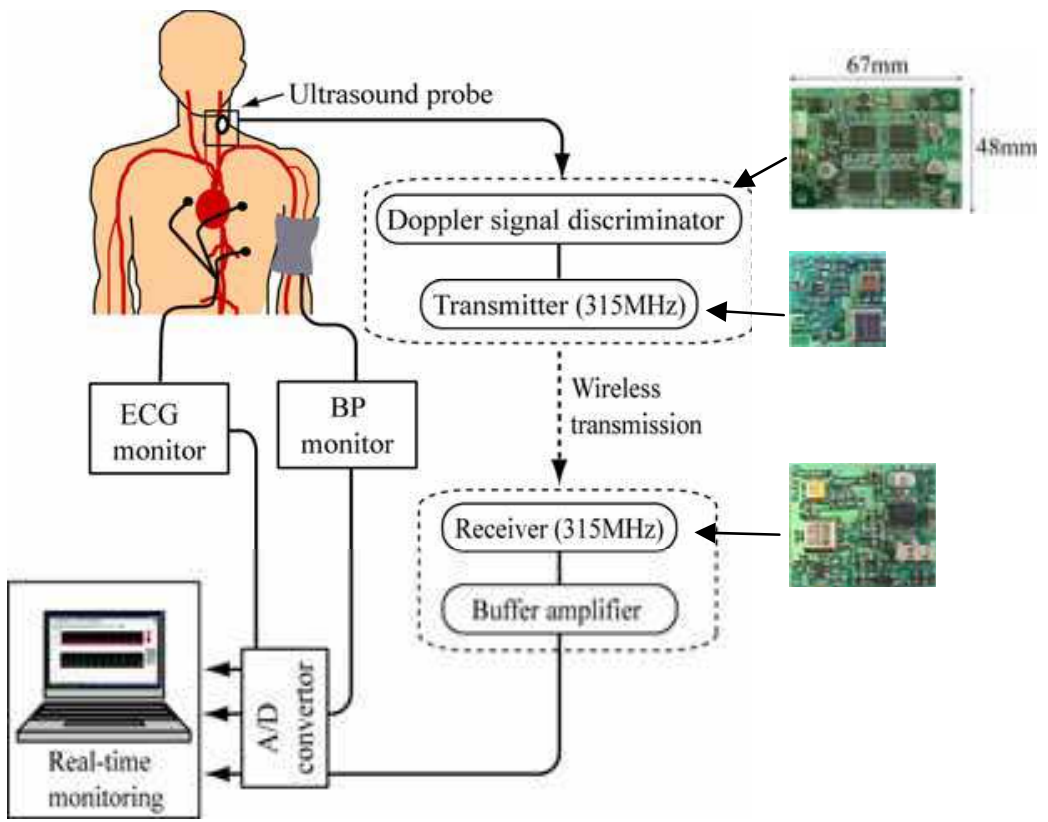

Fig. 1. Portable measurement system of blood flow velocity with synchronized measurements of electrocardiogram and blood pressure

Measurements of blood circulation during exercise stress or postural change was difficult. It provided high level artifacts caused by relative displacement of the ultrasound and artery and vibration of tissue, particularly measurement of blood flow in femoral artery (Dahnoun et al. 1990). Considering that we selected semicircular transducers to provide the wider and uniform transmitting ultrasonic beam (Zhang et al. 2002). Considering the depth of the arteries and the size of transducers, $2.0 \mathrm{MHz}$ was chosen as the transmitting ultrasonic frequency. The probe was designed with a small size $\left(\mathrm{W} 34 \times \mathrm{H} 20 \times \mathrm{D} 42 \mathrm{~mm}^{3}\right.$, approximately weighing $20 \mathrm{~g}$ ) using two piezoelectric zirconate titanate transducers (PZT) with a diameter of $15 \mathrm{~mm}$, where one was for transmitting ultrasound and the other was for receiving the Doppler echoes using continuous-wave ultrasound as shown in Fig. 2A. To make the emitting and receiving beams face to the target of blood vessels, a small angle of 184 degrees were set between the pair transducers for the carotid artery (Fig. 2B). The ultrasonic probe was attached to the left side of neck with 50 degrees of the Doppler angle of insonation as 
shown in Fig. 2C and was fixed it with band wound around the neck. An exact attachment position in measuring blood flow velocity in CCA is between the sternocleidomastoid muscle and the throat at a level between the fourth and fifth cervical vertebrae.

A transmitter transducer chosen for clinical use had an intensity output of $8 \mathrm{~mW} / \mathrm{cm}^{2}$ spatial peak-temporal average (SPTA) as measured by a $0.4 \mathrm{~mm}$ diameter needle hydrophone (ONDA, model HNV-0400). The ultrasonic output intensity was safe for the human tissue.

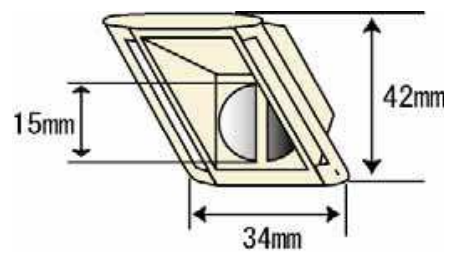

(A)

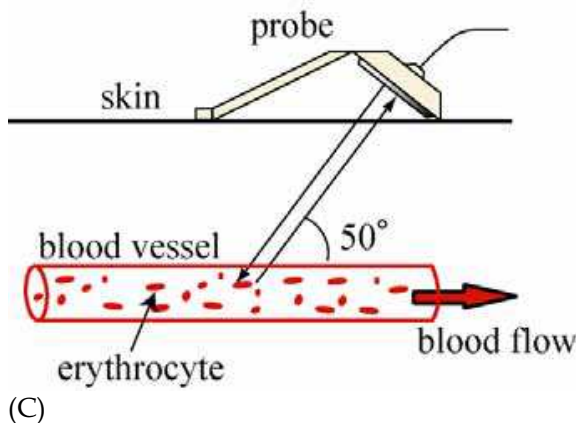

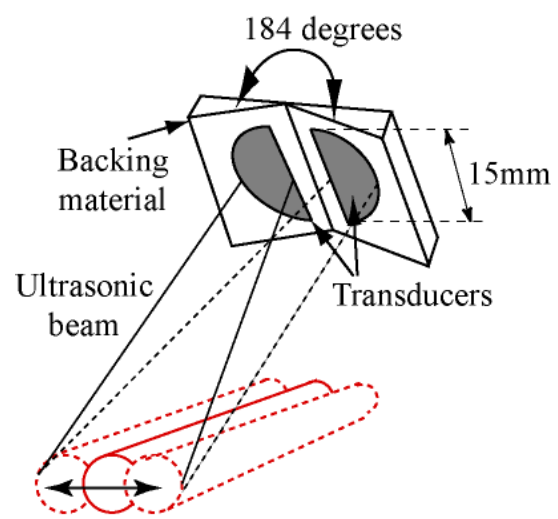

Displacement

of blood vessel

(B)

Fig. 2. (A) Dimension of ultrasound probe, (B) The design probe for wider transmitting ultrasonic beam, and (C) Doppler insonation angle

For the purpose use of healthcare application, the system was improved by miniaturizing the DSD, upgrading the probe with better attachment on the skin and developing the standalone real-time software package for measurement of blood flow velocity spectra with synchronized monitor of electrocardiogram (ECG) and blood pressure (BP). The DSD was miniaturized using mount-surface technique, and the downsized substrate size was $67 \times 48$ $\mathrm{mm}^{2}$ as shown in Fig. 1 . The substrate size of transmitter and receiver modules is $18.5 \times 18.5$ $\mathrm{mm}^{2}$ and $28 \times 24.5 \mathrm{~mm}^{2}$, respectively. The power consumption of the DSD and transmitter modules was reduced to $2.1 \mathrm{~W}$, therefore it was enabled battery installed in the portable system to be used approximately 10 hours. 


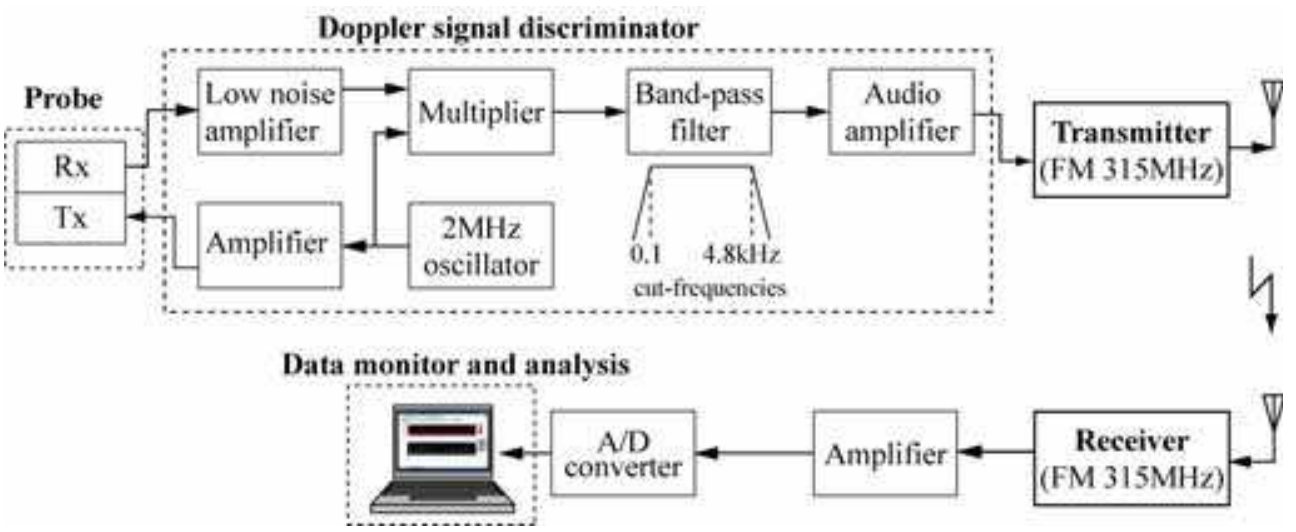

Fig. 3. Block diagram of the developed DSD

As illustrated in Fig. 3, square wave signal of $2 \mathrm{MHz}$ was oscillated at crystal oscillator. The signal was converted to sinusoidal signal at LC circuit which consists of an inductor and a capacitor. Then, it was buffered at operational amplifier (OPA) before $2 \mathrm{MHz}$ of ultrasound was emitted at the transmitting transducer. The emitted sinusoidal signal was set about 6.0 $\mathrm{V}_{\text {peak-to-peak. }}$ The detected signals at receiving transducer were including of Doppler shifted frequencies from the movement of blood flow (red blood cells), and vibration of tissues. After testing several kinds of circuits, we used the above DSD configuration to measure blood velocity for the purpose of telemetry (Azhim et al. 2007a).

A receiving Doppler signals were a few hundreds nanovolts which very small and weak signals. We used commercial available very-low-noise OPA (OP621, Burr Brown, US) to amplify the signals to tens of milivolts. After being amplified, the signals $\left(\omega_{\mathrm{D}}\right)$ were synchronously detected with $2.0 \mathrm{MHz}$ sinusoidal signals $\left(\omega_{0}\right)$ by commercial multiplier IC (AD835, Analog device, US). Typical outputs of multiplier generated the frequencies of sum $\left(\omega_{0}+\omega_{\mathrm{D}}\right)$ and difference $\left(\omega_{0}-\omega_{\mathrm{D}}\right)$, respectively. Consequently, Doppler signal could be derived from the output of difference frequencies, and the other unnecessary signals were filtered by band-pass filter (UAF4, Burr Brown, US). Considering of blood flow frequencies in particularly CCA, the cut-frequency (fc) of filter was set from 100 to $4800 \mathrm{~Hz}$.

\section{Real-time Monitor and Data Analysis}

After processing the Doppler signal at DSD, the signals were sampled to digital signal by A/D converter and fed to the computer for monitor and data analysis. We developed the stand-alone software to monitor blood spectral velocity with real-time as described below.

\subsection{Real-time Monitor}

In the real-time processing monitor implementation, two main specifications had been taken in account. First, the execution time of signal processing must be low, to avoid overloading the available system resources. Second, the output latency time had kept as short as possible (less than $100 \mathrm{~ms}$ ) to synchronize the sound with another output display (corresponding real-time spectrogram). 
The signal processing had been implemented through a program written in Visual $\mathrm{C}++{ }^{\circledR}$ for a stand-alone Windows ${ }^{\circledR}$ application as shown in Fig. 4 . The real-time spectrogram monitor was implemented by using loop timer method. Timer was set as $50 \mathrm{~ms}$ corresponding to the sampling data of 500 points. However, data were analyzed by using fast Fourier transforms (FFT) with multiples of 256 points of Hanning window. The spectrogram was processed using decimation in frequency (DIF) radix-2 FFT algorithm, which had smaller the discrete Fourier transform (DFT) computations in order to reduce the computation time. To increase the efficiency, decomposed of DFT was optimized by processing the real signal as called real-only FFT computation.

The average of CPU load, memory utilization, and computation time were measured in two laptop PCs of different performance as reported in previous study (Azhim et al. 2007a). Because of using set timer method, output latency was depended to timer rate, $50 \mathrm{~ms}$. If the signal processing time was less than set timer rate, latency time was constantly maintained. The computation time was lower than $1 \mathrm{~ms}$ when tested in the recent laptop PC. However, the computation time was quite larger, about $16 \mathrm{~ms}$ in the quite obsolete laptop PC, so that latency time to rendering spectrogram was still maintained at rate of $50 \mathrm{~ms}$.

Blood flow velocity spectra were measured for 1 minute in the relaxed sitting posture. Data collections were performed with synchronized monitoring of ECG and BP using a developed real-time processing monitor.

Systolic (SBP) and diastolic blood pressure (DBP) was collected at the left brachial artery by using the automatic blood pressure monitor (Tango, SunTech Medical, USA). Mean (MBP) and pulse blood pressure (PP) were calculated from DBP+ (SBP-DBP)/3 and SBP-DBP, respectively.

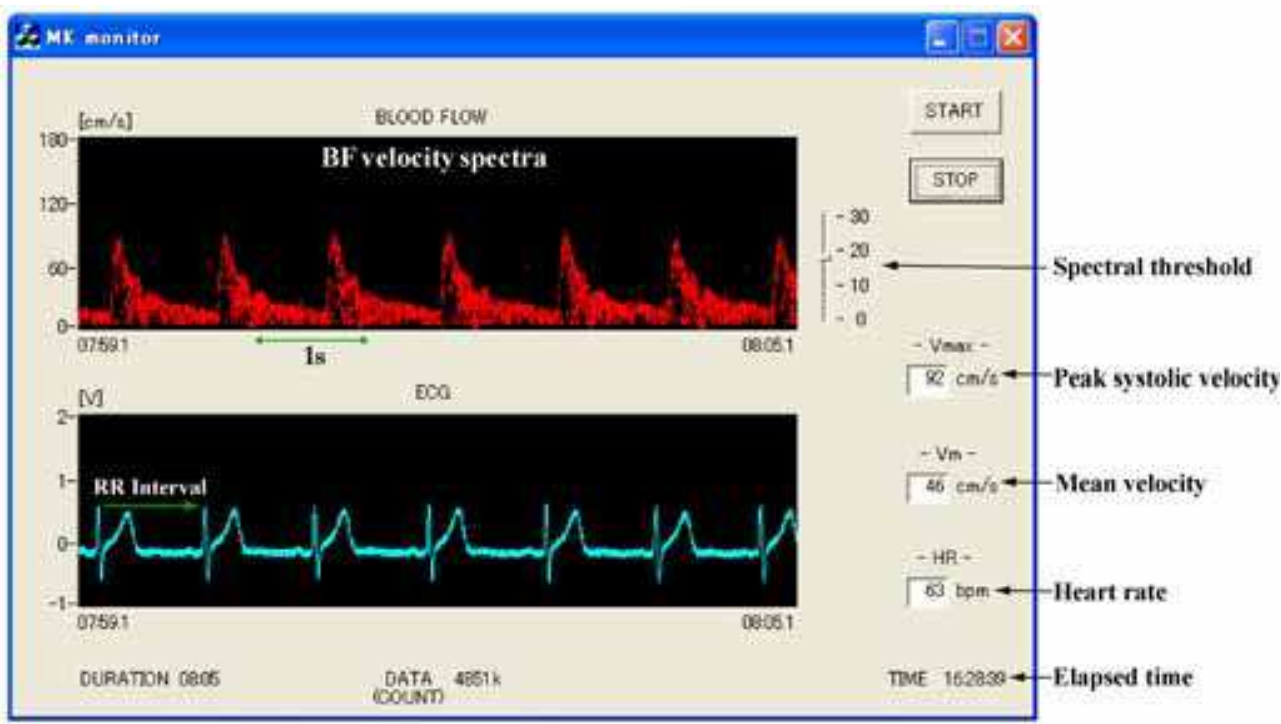

Fig. 4. The developed stand alone dialog software for real time monitoring of blood velocity spectra and ECG 


\subsection{Data Analysis}

The measured signals which included a low-frequency noise and a harmonics noise were filtered by band-pass filter of 0.1 to $4.8 \mathrm{kHz}$ in the DSD as shown in Fig. 3. From the frequency range, velocity spectra could be taken out by FFT analysis as monitored real-time in the developed dialog software (see Fig. 4). Estimation of flow velocity spectra $\left(V_{d}\right)$ was performed from the detected Doppler shifted frequency $\left(f_{d}\right)$ that was given by the classic equation: $V_{d}=c f_{d} / 2 f_{0} \cos \theta$, where, $c=1540 \mathrm{~m} / \mathrm{s}$, sound speed in human tissue; $\mathrm{f}_{0}$, an irradiated ultrasound frequency and $\theta=50$ degrees, the angle insonation.

The signals were acquired at $10 \mathrm{kHz}$ of fs through a $16 \mathrm{bit}-\mathrm{A} / \mathrm{D}$ converter (CBI-360116TR, Interface JAPAN). It was repeatedly analyzed by using FFT with successive $25.6 \mathrm{~ms}$, which were given by shifting $12.8 \mathrm{~ms}$ in turn. Therefore, an instantaneous spatial spectral frequency was calculated at $12.8 \mathrm{~ms}$ intervals with $39 \mathrm{~Hz}$ per point of frequency resolution.

Using a threshold method, flow velocity envelope $(\mathrm{Vp})$ was extracted from it spectra as shown in Fig. 5. Blood flow velocities in CCA were characterize to 5 feature points of waveform; peak systolic (S1), second systolic (S2), insicura between systole and diastole (I), peak diastolic (D) and end-diastolic minimum (d) velocities (Azhim et al., 2007a). An ensemble-averaging method was used to characterize and calculate blood velocities and its indices (Azhim et al., 2007a). We selected 30 consecutive cardiac cycles of those to characterize the feature points as represented in Fig. 6. From these, velocity indices were calculated from 1-d/S1, S2/S1-1 and 1-I/D as resistive (RI), velocity reflection (VRI) and vascular elasticity indices (VEI), respectively (Azhim et al., 2007b).

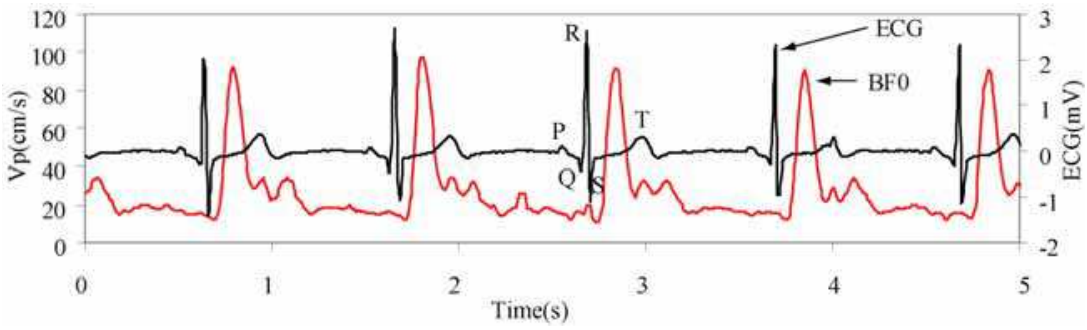

Fig. 5. Synchronization measurement of electrocardiogram (ECG) and blood velocity envelope (Vp).

As shown in Fig. 6, the velocity indices were calculated from the feature points of blood flow velocity. These indices were dimension-less and independent of the angle insonation. The RI was used as a typical peripheral vascular resistance index that can be calculated from waveforms as 1-d/S1, which the smaller RI the lower resistance and vice versa. The index was firstly used by Pourcelot on flow velocity waveform in CCA (Planiol et al., 1973; Pourcelot, 1976). Gosling et al. was firstly used velocity index of S1/S2 (as called A/B ratio) in CCA and superorbital arteries for detecting occlusive disease in the internal carotid artery (Gosling, 1977). The VRI was used in a manner similar to evaluate reflected wave velocity in second systolic velocity in CCA. In the previous study, the index of D/I was proposed and may be provided to evaluate the magnitude of vascular elastic recoil during cardiac diastole that is exerted by its smooth muscle cells (Azhim et al., 2007a). The VEI was used in the study to define the magnitude of vascular elasticity in a similar way. The velocity indices in 
CCA were found that changed by aging, regular exercise effect and gender difference (Azhim et al., 2007a; Azhim et al. 2007b).

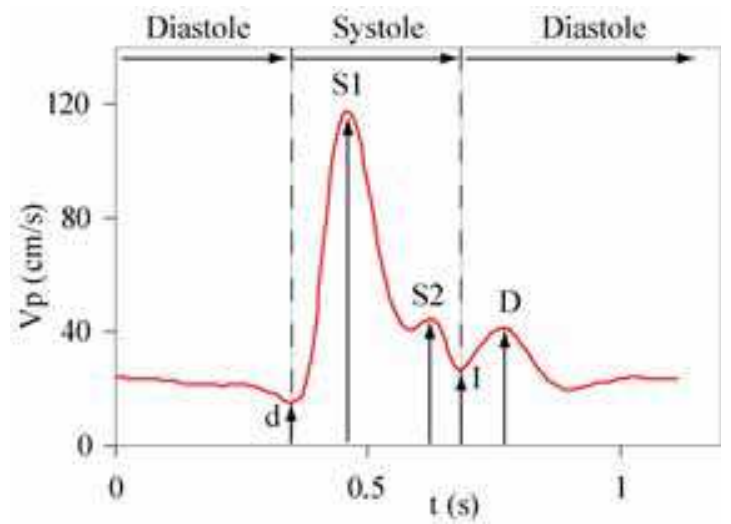

Fig. 6. Characteristic features on waveform: Ensemble-average velocities of 30 consecutive cardiac cycles in a young subject (21 years old, male). S1: the first peak systolic velocity wave (peak velocity), S2: the second systolic velocity wave, I: incisura between systole and diastole, D: the peak diastolic velocity wave, and d: the end-diastolic minimum velocity.

\subsection{Statistical Analysis}

Data were expressed as mean \pm standard error (SE). For overall view, Pearson's correlation analysis was performed to confirm the relationship between all outcome variables and the factors. As previous studies, we have reported that blood velocity waveforms in CCA had influenced by aging and regular exercise (Azhim et al., 2007a) and had significantly difference in gender (Azhim et al., 2007b). Hence, multivariate ANOVA test was used to determine the outcome variables (velocity data) that influenced by the multiple effects. The designed age-groups of significant pairwise differences were determined using Tukey's post-hoc test. After controlled for the effects of exercise and gender, correlation coefficient, R of all variables with age was determined (Table 2). The effects of exercise training are compared by ANOVA, which provides $\mathrm{P}$ values. The $\mathrm{P}$ value represents the effects of exercise training on the entire group, combining the classified decade-group as a single group. Gender difference was determined after adjustment for aging and exercise effects by least significant difference method, and as a categorical variable gender was coded as 1 for men and 2 for women (Table 3). The significance level, P was set at 0.05. Statistical analysis was performed using statistical package for the social sciences (SPSS).

\section{Measurement Data}

Using the developed portable measurement system as described above, data were collected in the study. Study was performed in a total of 286 putatively healthy subjects. We studied the selected 202 subjects between the ages of 20 and 69 years, from a cohort which normotensive (systolic blood pressure $\leqq 140 \mathrm{mmHg}$ ), normal body mass index (below 30 $\mathrm{kg} / \mathrm{cm}^{2}$ ), without any drug intake, and free of overt chronic diseases (including 
hyperlipidemia, diabetes, arrythmia) as assessed by medical history. There were 5 classified groups from 20-year-old to 69-year-old in 10-year-old intervals as shown in Table 2. Subjects were classified as exercised who performed regular aerobic exercise training more than 3 times per week.

\subsection{Anthropometric data for selected subjects}

Table 1 shows the characteristics of selected 202 subjects between the ages of 20 and 69 years. Anthropometric data for height, weight, body mass index, systolic, diastolic, mean, and pulse blood pressure are represented in mean, standard error, minimum and maximum values.

\begin{tabular}{|l|c|c|c|c|}
\hline & Mean & SE & Min & Max \\
\hline Height $(\mathrm{cm})$ & 165 & 0.7 & 148 & 184 \\
\hline Weight $(\mathrm{kg})$ & 59 & 0.9 & 39 & 93 \\
\hline BMI $\left(\mathrm{kg} / \mathrm{cm}^{2}\right)$ & 22 & 0.2 & 16 & 29 \\
\hline SBP $(\mathrm{mmHg})$ & 119 & 0.9 & 83 & 140 \\
\hline DBP $(\mathrm{mmHg})$ & 74 & 0.7 & 50 & 96 \\
\hline MBP $(\mathrm{mmHg})$ & 89 & 0.9 & 62 & 110 \\
\hline PP $(\mathrm{mmHg})$ & 45 & 0.7 & 17 & 70 \\
\hline Heart rate (beats / min $)$ & 73 & 0.8 & 48 & 100 \\
\hline
\end{tabular}

Table 1. Anthropometric data of the selected subjects. Data are mean, standard error (SE), minimum (Min) and maximum (Max). BMI, body mass index; SBP, systolic; DBP, diastolic; $\mathrm{MBP}$, mean; PP, pulse blood pressure.

\subsection{Reference data for normal velocities and the waveform indices}

Table 2 represents the reference data for normal CCA velocities and the indices between the third to seventh decades. Correlation coefficients of all variables with age were determined after controlling for the effects of exercise and gender. The velocities in $\mathrm{d}$ and I waves were not changed with age $(\mathrm{P}=\mathrm{NS})$. There were significant negative correlations in $\mathrm{S} 1$ and $\mathrm{D}$ velocities with age $(R=-0.615, P<0.001$ and $R=-0.248, P<0.001$, respectively). However, S2 velocity significantly positively correlated with age $(R=0.279, P<0.001)$. For velocity indices of RI and VEI, there were significant negative relation with age $(R=-0.606 \mathrm{P}<0.001$ and $\mathrm{R}=-$ $0.479, \mathrm{P}<0.001$, respectively), whereas there were significant positive relation with age for VRI $(R=0.798, P<0.001)$. From the data, it clearly shown that velocity continuously changed with advancing age as compared to third decade-group. The S1 and D velocities in seventh decade-group decreased $65 \%$ and $83 \%$, respectively compared to third decade-group. The S2 increased $16 \%$ in fifth decade-group and 13\% in seventh decade-group compared to third decade one. The indices of RI and VEI decreased $89 \%$ and $67 \%$ in seventh decade-group. Due to markedly decreased in S1, the VRI increased 34\% in seventh decade-group. 


\begin{tabular}{|c|c|c|c|c|c|c|}
\hline $\begin{array}{l}\text { Decade (years } \\
\text { old) }\end{array}$ & & $3^{\text {rd }}(20 \sim 29)$ & $4^{\text {th }}(30 \sim 39)$ & $5^{\text {th }}(40 \sim 49)$ & $6^{\text {th }}(50 \sim 59)$ & $7^{\text {th }}(60 \sim 69)$ \\
\hline \begin{tabular}{|l} 
Blood \\
velocities \\
$(\mathrm{cm} / \mathrm{s})$
\end{tabular} & $\mathrm{R}, \mathrm{P}$ & & & & & \\
\hline d & 0.084, NS & $20.38 \pm 0.49$ & $21.23 \pm 0.80$ & $23.04 \pm 1.06$ & $21.23 \pm 0.80$ & $20.07 \pm 1.32$ \\
\hline S1 & $-0.615,<0.001$ & $108.6 \pm 1.87$ & $102.0 \pm 3.05$ & $84.18 \pm 4.02$ & $76.0 \pm 3.048$ & $70.54 \pm 5.00$ \\
\hline S2 & $0.279,<0.001$ & $52.42 \pm 1.27$ & $59.21 \pm 2.06$ & $61.0 \pm 2.72$ & $59.96 \pm 2.06$ & $59.44 \pm 3.38$ \\
\hline I & 0.097, NS & $29.31 \pm 0.76$ & $31.55 \pm 1.23$ & $35.14 \pm 1.63$ & $30.64 \pm 1.23$ & $28.20 \pm 2.02$ \\
\hline D & $-0.248,<0.001$ & $43.57 \pm 0.78$ & $42.29 \pm 1.26$ & $42.54 \pm 1.66$ & $39.41 \pm 1.26$ & $36.38 \pm 2.07$ \\
\hline \multicolumn{7}{|l|}{ The indices (\%) } \\
\hline RI & $-0.606,<0.001$ & $80.8 \pm 0.5$ & $78.6 \pm 0.8$ & $72.4 \pm 1.1$ & $72.0 \pm 0.8$ & $72.2 \pm 1.3$ \\
\hline VRI & $0.798,<0.001$ & $-51.0 \pm 0.1$ & $-41.0 \pm 1.7$ & $-27.4 \pm 2.3$ & $-21.5 \pm 1.7$ & $-17.1 \pm 2.9$ \\
\hline VEI & $-0.479,<0.001$ & $33.1 \pm 1.0$ & $26.2 \pm 1.6$ & $0.18 .0 \pm 2.1$ & $21.8 \pm 1.6$ & $22.2 \pm 2.7$ \\
\hline
\end{tabular}

Table 2. The reference data indicated velocity and the indices between the third to the seventh age decades. The values indicated mean and standard error. $R$ indicates the values of partial correlation coefficient between variables and age after controlling for the effects of gender and exercise. $\mathrm{P}<0.001$ and NS indicated significant level and not significant, respectively. RI, resistive index; VRI, velocity reflection index; VEI, vascular elasticity.

To our knowledge, there were only three analogous studies for age-related decline in blood flow velocity and for reference data of normal velocities in CCA between multiple agegroups. In a first paper, Gregova et al. reported the peak systolic and end-diastolic velocities of CCA in 199 subjects which in the age range of 20-92 years. They suggested peak systolic velocity in CCA decreased with aging as the following yearly rate: in the right 6.44 $\mathrm{mm} / \mathrm{s} /$ year and left $7.39 \mathrm{~mm} / \mathrm{s} /$ year. The yearly decrease of end-diastolic velocity on the both sides was in range between 1.72 and $2.28 \mathrm{~mm} / \mathrm{s}$ (Gregova et al., 2004). In a second one, Scheel et al. presented the reference data of flow velocities in CCA and its index which performed in 78 healthy adults from 20 to 85 years old. They suggested that peak systolic velocity and end-diastolic minimum velocity decrease with age as following rate: $101 \pm 22$ $\mathrm{cm} / \mathrm{s}$ and $25 \pm 5 \mathrm{~cm} / \mathrm{s}$ for age-group of $20-39$ years, $89 \pm 17 \mathrm{~cm} / \mathrm{s}$ and $26 \pm 5 \mathrm{~cm} / \mathrm{s}$ for age-group of $40-59$ years, and $81 \pm 21 \mathrm{~cm} / \mathrm{s}$ and $20 \pm 7 \mathrm{~cm} / \mathrm{s}$ for age-group of $60-85$ years, respectively. In a third one, Fujishiro et al. measured blood velocity in the right common carotid artery in 140 normal healthy individuals in their teens to seventies using an ultrasonic quantitative flow measurement system (Fujishiro et al., 1982). As a result, they presented that S1 and d velocities markedly decreased with age, in which the values in the 70's were about $1 / 2$ and $2 / 3$ as small as that in the 20 's, respectively (Fujishiro et al., 1982). These findings were consistent with age-related decrease in blood flow velocities in CCA (Tanaka et al., 2000; Gregova et al., 2004; Azhim et al., 2007a, Nagamoto et al., 1992; Fujishiro and Yoshimura, 1982).

Most of other studies were not taken into account for the multiple effects on flow velocities in CCA. In the study, we demonstrated that there are multiple effects that probably alter blood velocity waveforms in CCA (Azhim et al., 2007a; Azhim et al., 2007b). We also found that blood velocity data are more sensitive compared to BP data. In the study, we found that 
not only S1 and d velocities, but also D velocity significantly decreased with age, whereas S2 velocity increased with age.

\subsection{Age-associated changes in flow velocity waveforms}

Fig. 8 represents the average values of five decade-groups as age-associated change blood velocity in CCA and the velocity indices. *Significant pairwise differences between third decade-group and the other designed decade-groups were determined using Tukey's post hoc test. The peak systolic and peak diastolic velocities were lower in the subjects over 40 years old $(\mathrm{P}<0.0001$ and $\mathrm{P}<0.0001$, respectively). The fourth decade-group had significant higher in S2 velocity compared to third decade-group. The d velocity had no significant different between the designed decade-groups. The fourth and over decade-groups had significant lower in the velocity indices of RI and VEI ( $P<0.0001$ and $\mathrm{P}<0.0001$, respectively). The VRI was higher in the decade-groups of third and over $(\mathrm{P}<0.0001)$.

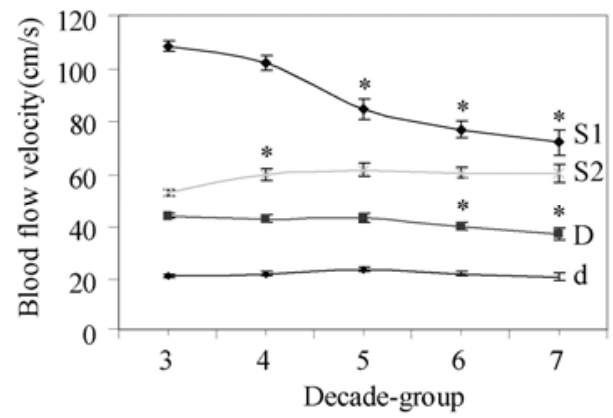

(A)

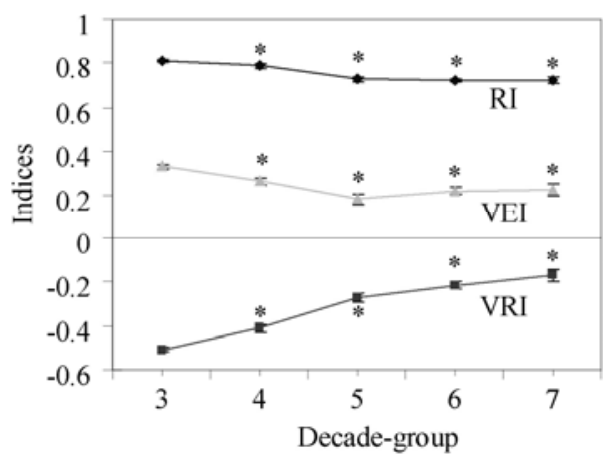

(B)

Fig. 8. Age-associated change in the feature points of velocity in CCA (A) and in its velocity indices (B). Data were mean and SE. *Significant pairwise differences versus third decadegroup were determined by Tukey's post-hoc test.

As we found that flow velocities in CCA decreased with age, other groups had reported that a comparable decrease in flow velocities with age (Satomura, 1959; Nagamoto et al., 1992; Fujishiro et al., 1982). Most of their studies only focused velocity waveforms, i.e. on the S1 and d velocities, and demonstrated that it decreased with age (Satomura, 1959; Nagamoto et al., 1992; Fujishiro et al., 1982).

In our study, we found that S1 and D velocities decreased continuously with age (by 9.67 and $1.55 \mathrm{~mm} / \mathrm{s} /$ year, respectively), and S2 velocity increased significantly wit h age (by 1.93 $\mathrm{mm} / \mathrm{s} /$ year). In hemodynamic studies, characteristic blood flow velocities in S1, S2, and d were more focused on their relationship either between aging and carotid diseases (Nagamoto et al., 1992; Fujishiro and Yoshimura, 1982; Gregova, 2004; Schmidt-Truchsass et al., 1999; Johannes et al., 2001; Scheel et al., 2000). Our results suggest that not only S1 and D velocities $(R=-0.612, P<0.001$ and $R=-0.248, P<0.001$, respectively), but also its indices of $R I$, VRI and VEI decreased continuously with age $(R=-0.606, P<0.001 ; R=-0.798, P<0.001 ; R=-$ $0.478, \mathrm{P}<0.001$, respectively after adjustment for gender and exercise effects). Although the 
latter velocities and the ratio could be measured easily using ensemble-average envelope velocities, only very few studies took this parameters into considerations with the intention of characterizing its associations with disease (Kaneko et al., 1978; Rutherford et al., 1977), aging and exercise training.

In the study, we also found that the decreases of $\mathrm{D}$ velocities and $\mathrm{D} / \mathrm{I}$ parameter, which were depended on arterial elastic recoil, were the important determinant as predictor of age. The decrease may be homeostatically related to the reduction of arterial compliance and elasticity with age (Schmidt-Trucksass et al., 1999; Lakatta, 2002; Tanaka et al., 2000). Ageassociated alterations in arterial properties comprised of structural, e.g. intima-media thickness (IMT), and functional, e.g. arterial elasticity, were related to changes of hemodynamic parameters particularly in peak blood flow velocity (Schmidt-Trucksass et al., 1999). Age was the strongest predictor in the decrease of S1, which may be a suitable parameter to evaluate the influence of aging or atherosclerotic risk factor on arterial structure and function (Schmidt-Trucksass et al., 1999).

Changes in the shape of velocity waveform may be quantified using RI as the most popular index. The index was originally used by Pourcelot on waveforms from CCA, as an indicator of peripheral vascular resistance beyond the measurement point (Planiol et al., 1973; Pourcelot, 1976), which the smaller RI the lower resistance and vice versa. It is dimensionless and independent of the angle insonation. It has consequently been widely used for the variety study of pathophysiological conditions including internal carotid stenosis (Pourcelot, 1976) and for the study of cerebral haemodynamics in neotanal and fetal (Permal, 1985; Donofrio et al., 2003). In the present study, we found that RI has significantly changed with age (see table 2).

The velocity ratio of S1/S2 is known that alters with aging and ICA disease (Baskett et al., 1977; Gosling, 1977; Prichard et al., 1979). Gosling demonstrated that S1/S2 ratio in sonograms from the CCA decreased with aging (Gosling, 1977). Baskett et al. used the ratio for screening and diagnosis of carotid junction disease (Baskett et al., 1977). They suggested that S1/S2 ratio less than 1.05 there is an $88 \%$ probability of disease at carotid junction (Baskett et al., 1977). We found that the index of S1/S2 has same tendency that significantly decrease continuously with age $(\mathrm{R}=-0.702, \mathrm{P}<0.001)$. In the study, velocity reflection index, as calculated from S2/S1-1, increased continuously with aging $(R=0.781, P<0.001)$. This index seems to have been improved in all age-groups by the training (see details in section 4.4). It is expected that decreased of peak systolic velocity S1 is associated with increased of second systolic velocity S2 with advancing age. The increasing of S2 may be related to the increased of wave reflection properties cause an increase in augmentation index (AI) and wasted ventricular energy (see details in section 4.5).

We could not determine the hemodynamic variables for velocity data in the seventies and over because of there are no healthy volunteers that participated in this investigation. Thus, further studies are needed.

\subsection{Effect of exercise on the entire groups}

Fig. 9 shows the effect of exercise training on peak systolic velocity and the velocity indices (P by ANOVA). As anticipated results, HR is lower in exercise-trained than in sedentary $(\mathrm{P}<0.0001)$. The $\mathrm{S} 1$ velocities are significantly higher in exercise-trained than in sedentary $(\mathrm{P}=0.009)$. The others $(\mathrm{S} 2, \mathrm{D}, \mathrm{d})$ have no significant differences for the exercise effect $(\mathrm{P}=\mathrm{NS})$. Due to the significant increase in S1, it is reasonable that the RI and VRI in the exercise- 
trained are significantly higher $(\mathrm{P}<0.008)$ and lower $(\mathrm{P}=0.0008)$, respectively. The VEI was not found significant difference between two groups $(\mathrm{P}=0.093)$.

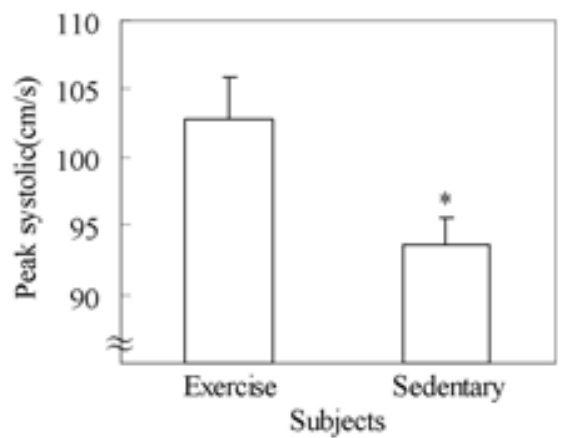

(A)

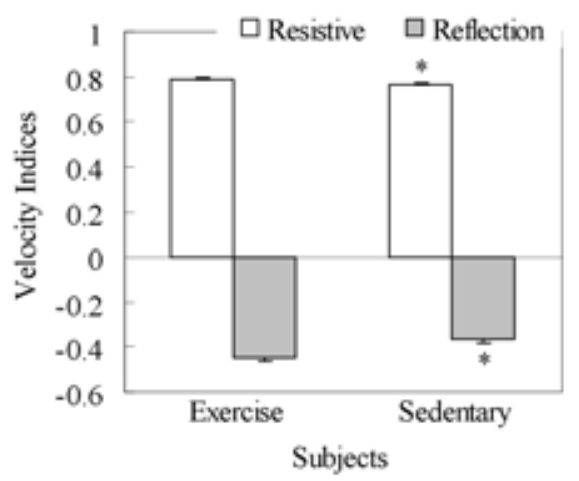

(B)

Fig. 9. Peak systolic velocity and the velocity indices in exercise-trained and sedentary subjects. ${ }^{*} \mathrm{P}<0.05$ significance between exercise-trained and sedentary peers.

One of most pronounced cardiovascular adaptation to aerobic exercise training is a lowered HR in the resting (Chen et al., 1997; Goldsmith et al., 2000). For instance, it has been reported that trained runners often possess resting HR lower than 50 bpm (Costill, 1986). Similarly, lower resting HR have been shown to occur in sedentary individuals after they have been exposed to effective aerobic exercise training (Maciel et al., 1985). In our cross-sectional study, HR are lower in regular exercise trained than in the sedentary peers. As anticipated, the resting HR decreased in previously sedentary young subjects after exercise intervention. As shown in Fig. 10, there are typical blood velocity waveforms in three age-groups. Peak systolic velocities are seen extremely sharper and higher in third decade-group, exercisetrained sixth decade- and seventh decade-persons. All blood flow velocity waveforms are not significantly changed in who regularly performed aerobic exercise training in three agegroups. The velocities are sharper and higher than those of sedentary peers in the especially, elderly age. The adaptations of blood flow to regular exercise are similarly changed with aging ( $\mathrm{P}=\mathrm{NS}$ by ANOVA). The patterns of blood flow waveforms are no significance difference between young and older exercise-trained. As we reported in previous study, there were no differential exercise effects in the designed age-groups (Azhim et al., 2007).

S1 velocities have a significant difference between exercise-trained and sedentary adults. Due to the increased of S1 velocities, the VEI and RI indicate a similar tendency change with the training. Thus, training exercise is a predictor of increasing S1 velocities as a suitable parameter to evaluate the effect of training exercise. The decreased of resting HR is associated with the increased of S1 velocities and RI and the decreased of VRI with training. We can only speculate on one of the adaptation of cardiovascular systems to regular aerobic exercise training improved arterial compliance and increased stroke volume in the present study. The increased of S1 velocities seem to reflect the changes of several structural and functional parameters including IMT and arterial compliance related to smooth muscle behavior in a similar way (Schmidt-Trucksass et al., 1999). Regular exercise training exerted a decreased HR with the association of increased blood velocity waveforms in CCA. 
We also found that the ability of regular aerobic exercise to improve flow velocity waveform in particularly older population was not related on blood pressure. This was the first finding in age-associated deterioration in blood velocity waveforms of CCA could be modified favorably by regular exercise aerobic exercise (Azhim et al., 2007a).
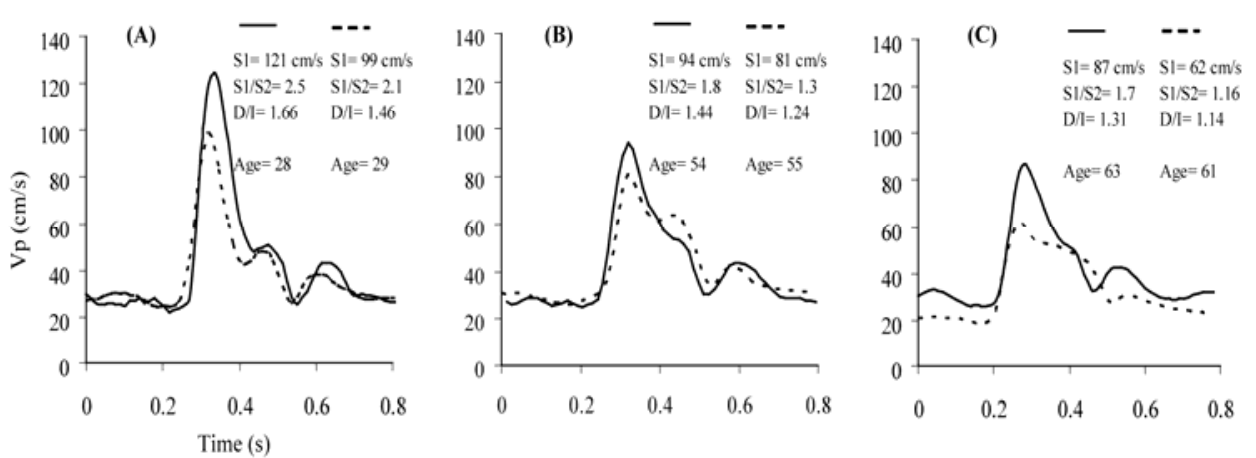

Fig. 10. Comparisons of typical blood flow velocity waveforms for regular aerobic exercisetrained (solid line) and sedentary adults (dashed line) in the third (A), sixth (B), and seventh (C) decade-groups. Regular exercise may retard age-associated diminishing in blood flow velocity waveforms in human.

\subsection{Gender difference in the velocities and waveform indices}

Table 3 represents the gender difference in the outcome hemodynamic variables and anthropometric data. Generally men had larger body stature and mass. As shown in the result, height, weight and BMI are significantly higher in men $(\mathrm{P}<0.001)$. Men had larger SBP and PP compared to women $(\mathrm{P}<0.05)$. However, we could not found the gender difference in $\mathrm{DBP}$ and $\mathrm{MBP}(\mathrm{P}=\mathrm{NS})$. There was remarkable gender difference in flow velocities, expected for $\mathrm{S} 1$ velocity as shown in Table 3. It is shown that all velocity indices were significant different between men and women $(\mathrm{P}<0.001)$. There was no gender difference in heart rate $(\mathrm{P}=\mathrm{NS})$.

The findings present the effect of gender in the role body height and weight on arterial hemodynamics in carotid blood flow velocity waveforms. As we found in the study, the women had a lower brachial systolic pressure and carotid systolic velocity, whereas had higher end-diastolic and second systolic velocities. Therefore, the velocity indices in vascular resistive and elastic recoil were lower in women. However, wave reflection index was higher in women than in men.

The augmented secondary peak in the carotid systolic pressure waveform was attributed to wave reflection (Murgo et al., 1980). A major determinant of intensity of wave reflection was the distance to reflecting sites. Previous investigators suggested body height was a significance inverse determinant of augmentation due to earlier wave reflection (London et al., 1995). Some reports presented that the greater of wave reflection in women was associated with shorter body height, due to shorter distance to reflecting sites (Mitchell et al., 2004). They reported that augmentation wave pressure reflection was useful for assessments of cardiovascular risk and clinical potential (Marchais et al., 1993; Mitchell et al., 2004; Nichols et al., 2005). However, the importance of reflected flow waves was not emphasized 
until relatively recently (Nichols et al., 2005). In the study, augmentation of reflected flow wave had highly correlated with that of reflected pressure wave. It was potential to determine wave reflection from its flow velocity components. Velocity wave reflections were highly correlated to its pressure components $\left(R^{2}=0.836\right)$ (Azhim et al., 2007c).

\begin{tabular}{|l|l|l|}
\hline & Men & Women \\
\hline Height $(\mathrm{cm})$ & $170 \pm 0.6$ & $157 \pm 0.8^{* *}$ \\
\hline Weight $(\mathrm{kg})$ & $64 \pm 0.9$ & $51 \pm 1.1^{* *}$ \\
\hline BMI $\left(\mathrm{kg} / \mathrm{cm}^{2}\right)$ & $22 \pm 0.3$ & $20 \pm 0.4^{* *}$ \\
\hline SBP $(\mathrm{mmHg})$ & $121 \pm 1.1$ & $116 \pm 1.4^{*}$ \\
\hline DBP $(\mathrm{mmHg})$ & $75 \pm 0.9$ & $73 \pm 1.2$ \\
\hline MBP $(\mathrm{mmHg})$ & $90 \pm 0.9$ & $88 \pm 1.1$ \\
\hline PP $(\mathrm{mmHg})$ & $46 \pm 0.8$ & $42 \pm 1.1^{*}$ \\
\hline Heart rate $($ beats /min) & $73 \pm 0.8$ & $73 \pm 1.3$ \\
\hline Blood velocity $(\mathrm{cm} / \mathrm{s})$ & & \\
\hline d & $18.8 \pm 0.5$ & $23.0 \pm 0.6^{* *}$ \\
\hline S1 & $98.8 \pm 1.9$ & $99.4 \pm 2.4$ \\
\hline S2 & $49.0 \pm 1.2$ & $62.4 \pm 1.6^{* *}$ \\
\hline I & $27.0 \pm 0.7$ & $34.0 \pm 0.9^{* *}$ \\
\hline D & $40.0 \pm 0.7$ & $44.9 \pm 0.9^{* *}$ \\
\hline Velocity indices $(\%)$ & & \\
\hline Resistive & $80.1 \pm 0.5$ & $76.4 \pm 0.6^{* *}$ \\
\hline Reflection & $-48.1 \pm 1.0$ & $-36.0 \pm 1.3^{* *}$ \\
\hline Vascular elastic recoil & $31.8 \pm 0.9$ & $24.4 \pm 1.2^{* *}$ \\
\hline
\end{tabular}

Table 3. Gender difference in the outcome variables and anthropometric data. The values were mean and SE after adjustment for the aging and exercise effects. BMI: body mass index; SBP: systolic, DBP: diastolic, MBP: mean, PP: pulse blood pressure. ${ }^{*} \mathrm{P}<0.05,{ }^{* *} \mathrm{P}<0.001$ indicated the significant levels.

Epidemiological studies based on brachial artery pressure indicate that SBP were lower in young premenopausal women than in age-matched men (London et al., 1995; Kannel et al., 1985). The results were consistent finding that women had lower blood pressure in brachial artery than in men. Generally, SBP and PP increased as a pulse travels from aorta toward the peripheral, the increase being all the more pronounced as the distance of pulse propagation (London et al., 1995; Latham et al., 1985). Women had larger reflected waves than men, in part due to shorter body height and closer physical proximity between heart and reflecting sites. However, body height was not sufficient to fully explain higher reflected wave flow and pressure in women. In the study we indicated that the reflected wave had higher in women and was significantly correlated to body height and weight. Although, pressure wave reflection and propagation are known recently to correlate with body height (London et al., 1995; Latham et al., 1985; Mitchell et al., 2004), however, we also found that increased reflected wave was partially contributed by decreased body weight and increased heart rate level. The gender difference in arterial hemodynamics in carotid blood velocity waveforms is probably accounted for body height and weight. 
It had been reported that women had lower carotid artery distensibility compared with men (Ylitalo et al., 2000). From the findings of present study, we agreed that women had lower arterial elasticity using the proposed velocity indices. The difference in the velocities and its indices were related to smaller body size in women that largely accounted for the gender differences. However, the difference in velocity indices was also influenced by concentrations of estrogen in hormone status of women (Krejza et al., 2001).

The gender difference in velocity waveforms in CCA found in this population was not depended on blood pressure. It was demonstrated that the gender difference in blood velocity waveforms of CCA are not directly linked to it pressure waveforms (Azhim et al., 2007b).

Although the finding in the effect of increased wave reflection in arterial system on body height was consistent, because the relation of body weight and body fat on the artery stiffness and flow velocities were largely unknown, further investigations are needed. The Doppler angle of insonation was important because it must be taken into account when calculating blood flow velocity from the Doppler shift frequency. However, the velocity indices of were independent of the insonating angle so that the assessments of hemodynamics were more accurate and reliable.

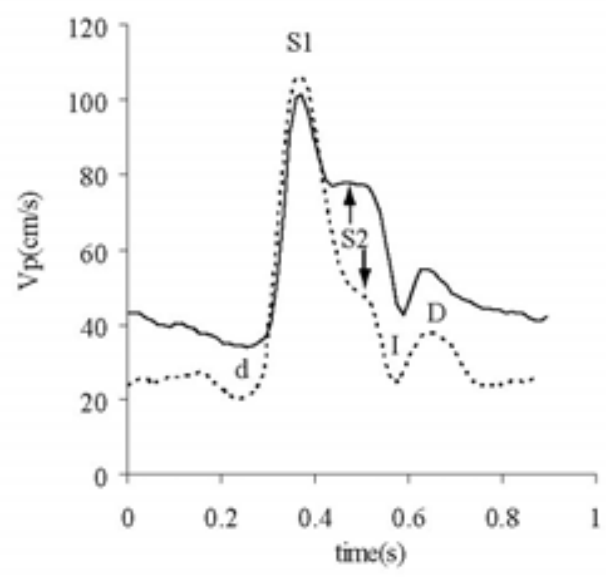

Fig. 11. Comparison of typical flow velocity waveforms in CCA for gender difference of man (dashed line) and woman (solid line). Subject's details were $171 \mathrm{~cm}, 65 \mathrm{~kg}$, BMI: 22 $\mathrm{kg} / \mathrm{m}^{2}$, age: 23 years for man and $154 \mathrm{~cm}, 48 \mathrm{~kg}$, BMI: $20 \mathrm{~kg} / \mathrm{m}^{2}$, age: 25 years for woman.

\section{Conclusion}

In the chapter, we have presented first, the portable measurement system has developed for ambulatory and nonivansive determination of blood circulation with synchronized of blood pressure and ECG signals, which has potential to provide the critical information in clinical and healthcare applications. Second, there are multiple factors which have effects on blood velocity waveforms in CCA. Regular exercise training is able to improve age-associated decrease blood velocity in CCA with similar effect between young and older exercisetrained. The velocity waveform patterns have no significantly change with age in entire 
groups who regularly performed aerobic exercise. Gender-associated difference in the outcome of velocities and the indices is also found in the study. Reference data for normal velocities and the indices in CCA are determined after adjustment for the effects of age, gender, and exercise training. Reductions in blood flow velocities are believed to have contributed significantly to the pathophysiology of age-associated increase in not only cardiovascular but also cerebrovascular diseases. The findings have potentially important clinical and healthcare requirements for prevention of cardiovascular diseases.

\section{References}

Azhim, A.; Akioka, K.; Akutagawa, M.; Hirao, Y.; Yoshizaki, K.; Obara, S.; Nomura, M.; Tanaka, H.; Yamaguchi, H. \& Kinouchi, Y. (2007c). Effects of aging and exercise training on the common carotid blood velocities in healthy men. Conf. Proc. IEEE Eng. Med. Biol. Soc., vol. 1, pp. 989-99

Azhim, A.; Katai, M.; Akutagawa, M.; Hirao, Y.; Yoshizaki, K.; Obara, S.; Nomura, M.; Tanaka, H.; Yamaguchi, H. \& Kinouchi, Y. (2008) Measurement of blood flow velocity waveforms in the carotid, brachial and femoral arteries during head-up tilt. Journal of Biomedical \& Pharmaceutical Engineering, vol. 2-1, pp. 1-6

Azhim, A.; Akioka, K.; Akutagawa, M.; Hirao, Y.; Yoshizaki, K.; Obara, S.; Nomura, M.; Tanaka, H.; Yamaguchi, H. \& Kinouchi, Y. (2007b). Effect of gender on blood flow velocities and blood pressure: Role of body weight and height. Conf Proc IEEE Eng Med Biol Soc., pp. 967-970

Azhim, A.; Katai, M.; Akutagawa, M.; Hirao, Y.; Yoshizaki, K.; Obara, S.; Nomura, M.; Tanaka, H.; Yamaguchi, H. \& Kinouchi, Y. (2007a). Exercise improved ageassociated changes in the carotid blood velocity waveforms. Journal of Biomedical $\mathcal{E}$ Pharmaceutical Engineering, vol. 1-1, pp. 17-26

Azhim, A.; Kinouchi, Y. \& Akutagawa, M. (2009). Biomedical Telemetry: Technology and Applications, In: Telemetry: Research, Technology and Applications, Diana Barculo and Julia Daniels, (Eds.), Nova Science Publishers, New York, ISBN: 978-1-60692-509-6 (2009)

Baskett, J. J.; XBeasley, J. J.; Murphy, G. J.; Hyams, D. E. \& Gosling, R. G. (1977). Screening for carotid junction disease by spectral analysis of Doppler signals. Cardiovasc Res., vol. 11(2), pp. 147-55

Chen, C. \& Dicarlo, SE. (1997). Endurance exercise training-induces resting bradycardia. Sport Med. Training Rehabil., vol. 8, pp. 37-77

Costill, D. (1986). Inside running: basics of sports physiology. Benchmark Press, Indianapolis, pp. 15

Dahnoun, N.; Thrush, A.J.; Fothergill, J.C. \& Evans, D.H. (1990). Portable directional ultrasonic Doppler blood velocimeter for ambulatory use. Med Biol Eng Comput, vol. 28, pp. 474-482

Darne, B.; Girerd, X.; Safar, M.; Cambien, F. \& Guize L. (1989) Pulsatile versus steady component of blood pressure: a cross-sectional analysis on cardiovascular mortality. Hypertension, vol. 13, pp. 392-400

Donofrio MT, Bremer YA, Schieken RM, Gennings C, Morton LD, Eidem BW, Cetta F, Falkensammer CB, Huhta JC and Kleinman CS. Autoregulation of cerebral blood 
flow in fetuses with congenital heart disease: The brain sparing effect. Pediatr Cardiol 2003; 24: 436-443

Fujishiro, K. \& Yoshimura, S. (1982). Haemodynamic change in carotid blood flow with age. J. Jekeikai Med, vol. 29, pp. 125-138

Goldsmith, R.L.; Bloomfeld, D.M. \& Rosenwinkel, E.T. (2000). Exercise and autonomic function. Coron. Artery Dis., vol. 11, pp. 129-135

Gosling, R.G. (1977). Extraction of physiological information from spectrum-analysed Doppler-shifted continuous wave ultrasound signals obtained non-invasively from the arterial system. In: Institute of Electrical Engineers medical electronics monographs, Hill D.W. \& Watson B.W., (Eds), pp. 73-125, Peter Peregrinus, Stevenage

Gregova, D.; Termerova, J.; Korsa, J.; Benedikt, P.; Peisker, T.; Prochazka, B.; \& Kalvach, P. (2004) Age dependence of flow velocities in the carotid arteries. Ceska a Slovenska Neurologie a Neurochirurgie, vol. 67 (6), pp. 409-414, 2004 (abstract in English)

He, J.; Kinouchi, Y.; Iritani, T.; Yamaguchi, H. \& Miyamoto, H. (1992). Telemetering blood flow velocity and ECG during exercise. Innov Tech Biol Med., vol. 13, pp. 567-577

He, J.; Pan, A. W.; Ozaki, T.; Kinouchi, Y. \& Yamaguchi, H. (1996). Three channels telemetry system: ECG, blood velocities of the carotid and the brachial arteries. Biomedical Engineering Applications Basis Communications, vol. 8, pp. 364-369

Jiang, Z-L.; He, J.; Yamaguchi, H.; Tanaka, H. \& Miyamoto, H. (1994). Blood flow velocity in common carotid artery in humans during breath-holding and face immersion. Aviat Space Environ Med., vol. 65, pp. 936-943

Jiang, Z-L.; Yamaguchi, H.; Takahashi, A.; Tanabe, S.; Utsuyama, N.; Ikehara, T.; Hosokawa, K.; Tanaka, H.; Kinouchi, Y. \& Miyamoto, H. (1995). Blood flow velocity in the common carotid artery in humans during graded exercise on a treadmill. Eur J Appl Physiol, vol. 70, no. 3, pp. 234-239

Johannes, S.; Michael, S.; Thomas, W.; Wolfgang, R.N.; Markus, V.; Markus, L. \& Stefan F. (2001). Quantification of blood flow in the carotid arteries comparison of Doppler ultrasound and three different phase-contrast magnetic resonance imaging sequences. Investigate Radiology, vol. 36-11, pp. 642-647

Kaneko, Z.; Shiraishi, J.; Inaoka, H.; Furukawa, T. \& Sekiyama, M. (1978). Intra- and extracerebral hemodynamics of migrainous headache. In: Current concepts in migraine research, Greene, R. (Ed.), pp. 17-24, Raven, New York

Kannel, W. B. \& Stokes III, J. (1985). Hypertension as a cardiovascular risk factor. In: Handbook of Hypertension. Clinical Aspects of Hypertension, Robertson, J.I.S. (Ed.), pp. 15-34, Elsevier Science Publishing, New York

Krejza, J.; Mariak, Z.; Huba, M.; Wolczynski, S. \& Lewko, J. (2001). Effect of endogenous estrogen on blood flow through carotid arteries. Stroke, vol. 32, pp. 30-36

Lakatta, E.G. (2002). Age-associated cardiovascular changes in health: Impact on cardiovascular disease in older persons. Heart Fail Rev, vol. 1, pp. 29-49

Latham, R. D.; Westerhof, N.; Sipkema, P.; Rubal, B. J.; Reuderink, P. \& Murgo, J. P. (1985). Regional wave travel and reflections along the human aorta: A study with six simultaneous micromanometric pressures. Circulation, vol. 72, pp. 1257-1269

London, G.M.; Guerin, A.P.; Pannier, B.; Marchais, S.J. \& Stimpel, M. (1995). Influence of sex on arterial hemodynamics and blood pressure: Role of body height. Hypertension, vol. 26, pp. 514-519 
Maciel, B.C.; Gallo, L.; Marin-Neto, JA; Lima-Filho, E.C. \& Mancoy, J.C. Parasympathetic contribution to bradycardia induced by endurance training in man. Cardiovasc Res 1985; 19: 642-648

Marchais, S.J.; Guerin, A.P.; Pannier, B.M.; Levy, B.I.; Safar, M.E. \& London, G.M. (1993). Wave reflections and cardiac hypertrophy in chronic uremia: Influence of body size. Hypertension, vol. 22, pp. 876-883

Mitchell, G. F.; Parise, H.; Benjamin, E. J.; Larson, M. G.; Keyes, M. J.; Vita, J. A.; Vasan, R. S. \& Levy, D. (2004). Changes in arterial stiffness and wave reflection with advancing age in healthy men and women: The Framingham Heart Study. Hypertension, vol. 43, pp.1239-1245

Murgo, J.; Westerhof, N.; Giolma, J. P. \& Altobelli, S. (1980). Aortic impedance in normal man: relationship to pressure waveforms. Circulation, vol. 62, pp. 105-16

Nagatomo, I.; Nomaguchi M. \& Matsumoto K. (1992). Blood flow velocity waveform in the common carotid artery and its analysis in elderly subjects. Clin Auton Res., vol. 2(3), pp. $197-200$

Nichols, W. W. \& O'Rourke, M. F. (2005) McDonald's Blood Flow in Arteries: Theoretic, Experimental and Clinical Principles. Hodder Arnold, ISBN 0-340-80941-8, London

Permal JM. Neonatal cerebral blood flow velocity measurement. Clin Perinatol 1985; vol. 12, pp. 179-193

Planiol T and Pourcelot L. (1973). Doppler effects study of the carotid circulation, In: Ultrasonics in medicine, Vlieger, M.; White, D.N. \& McCready, V.R. (Eds), pp. 141147, Elsevier, New York

Pourcelot L. (1976). Diagnostic ultrasound for cerebral vascular diseases, In: Present and future of diagnostic ultrasound, Donald, I. \& Levi, S., (Eds), pp. 141-147, Kooyker, Rotterdam

Prichard, D. R.; Martin, T. R. \& Sherriff, S. B. (1979). Assessment of directional Doppler ultrasound techniques in the diagnosis of carotid artery diseases. Journal of Neurology, Neurosurgery, and Psychiatry, vol. 42, pp. 563-568

Rutherford, R.B; Hiatt, W.R. \& Kreuter, E.W. (1977). The use of velocity wave form analysis in the diagnosis of carotid artery occlusive. Surgery, vol. 82-5, pp. 695-702

Satomura S. (1959). Study of the flow pattern in peripheral arteries by ultrasonics. J. Acoust Soc Jpn, vol. 15, pp. 151-158

Scheel, P.; Ruge, C. \& Schoning, M. (2000). Flow velocity and flow volume measurements in the extracranial carotid and vertebral arteries in healthy adults: Reference data of age. Ultrasound Med Biol., vol. 26, pp. 1261-1266

Schmidt-Trucksass, A.; Grathwohl, D.; Schmid, A.; Boragk, R.; Upmeier, C.; Keul, J. \& Huonker M. (1999). Structural, functional, and hemodynamic changes of the common carotid artery with age in male subjects. Arterioscler Thromb Vasc Biol., vol. 19, pp. 1091-1097

Tanaka, H.; Dinenno, F. A.; Monahan, K. D.; Christopher, M. C.; Christopher, A. D. \& Seals, D.R. (2000). Aging, habitual exercise, and dynamic arterial compliance. Circulation, vol. 102, pp. 1270-1275

Ylitalo, A.; Airaksinen, K.E.; Hautanen, A. M.; Kupari, A.; Carson, M.; Virolainen, J.; Savolainen, M.; Kauma, H.; Kesaniemi, Y.A.; White, P.C. \& Huikuri, H.V. (2000). Baroreflex sensitivity and variants of the renin angiotensin system genes. J. Am. Coll. Cardiol., vol. 35, pp. 194-200 
Yuhi, F. (1987). Diagnostic characteristics of intracranial lesions with ultrasonic Doppler sonography on the common carotid artery. Med J Kagoshima Univ., vol. 39, pp. 183225 (abstract in English)

Zhang, D.; Hirao, Y.; Kinouchi, Y.; Yamaguchi, H. \& Yoshizaki, K. (2002). Effects of nonuniform acoustic fields in vessels and blood velocity profiles on Doppler power spectrum and mean blood velocity. IEICE Transactions on Information and Systems, vol. E85-D, pp. 1443-1451 


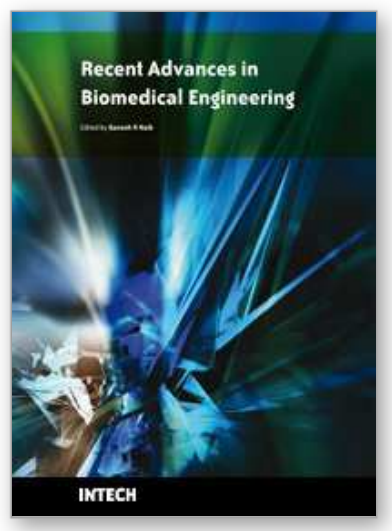

\author{
Recent Advances in Biomedical Engineering \\ Edited by Ganesh R Naik
}

ISBN 978-953-307-004-9

Hard cover, 660 pages

Publisher InTech

Published online 01, October, 2009

Published in print edition October, 2009

The field of biomedical engineering has expanded markedly in the past ten years. This growth is supported by advances in biological science, which have created new opportunities for development of tools for diagnosis and therapy for human disease. The discipline focuses both on development of new biomaterials, analytical methodologies and on the application of concepts drawn from engineering, computing, mathematics, chemical and physical sciences to advance biomedical knowledge while improving the effectiveness and delivery of clinical medicine. Biomedical engineering now encompasses a range of fields of specialization including bioinstrumentation, bioimaging, biomechanics, biomaterials, and biomolecular engineering. Biomedical engineering covers recent advances in the growing field of biomedical technology, instrumentation, and administration. Contributions focus on theoretical and practical problems associated with the development of medical technology; the introduction of new engineering methods into public health; hospitals and patient care; the improvement of diagnosis and therapy; and biomedical information storage and retrieval. The book is directed at engineering students in their final year of undergraduate studies or in their graduate studies. Most undergraduate students majoring in biomedical engineering are faced with a decision, early in their program of study, regarding the field in which they would like to specialize. Each chosen specialty has a specific set of course requirements and is supplemented by wise selection of elective and supporting coursework. Also, many young students of biomedical engineering use independent research projects as a source of inspiration and preparation but have difficulty identifying research areas that are right for them. Therefore, a second goal of this book is to link knowledge of basic science and engineering to fields of specialization and current research. The editor would like to thank the authors, who have committed so much effort to the publication of this work.

\title{
How to reference
}

In order to correctly reference this scholarly work, feel free to copy and paste the following:

Azran Azhim and Yohsuke Kinouchi (2009). Arterial Blood Velocity Measurement by Portable Wireless System for Healthcare Evaluation: the Related Effects and Significant Reference Data, Recent Advances in Biomedical Engineering, Ganesh R Naik (Ed.), ISBN: 978-953-307-004-9, InTech, Available from:

http://www.intechopen.com/books/recent-advances-in-biomedical-engineering/arterial-blood-velocitymeasurement-by-portable-wireless-system-for-healthcare-evaluation-the-relate

\section{INTECH}

open science | open minds

\section{InTech Europe}

University Campus STeP Ri

\section{InTech China}

Unit 405, Office Block, Hotel Equatorial Shanghai 
Slavka Krautzeka 83/A

51000 Rijeka, Croatia

Phone: +385 (51) 770447

Fax: +385 (51) 686166

www.intechopen.com
No.65, Yan An Road (West), Shanghai, 200040, China 中国上海市延安西路65号上海国际贵都大饭店办公楼405单元 Phone: +86-21-62489820

Fax: +86-21-62489821 
(C) 2009 The Author(s). Licensee IntechOpen. This chapter is distributed under the terms of the Creative Commons Attribution-NonCommercial-ShareAlike-3.0 License, which permits use, distribution and reproduction for non-commercial purposes, provided the original is properly cited and derivative works building on this content are distributed under the same license. 